\title{
MOVIMIENTO INDÍGENA Y RETOS electorales en Colombia:

\author{
regreso de lo indio \\ para una apuesta nacional
}

\author{
VIRGINIE LAURENT \\ INVESTIGADORA ASOCIADA ICANH \\ virlaurent@hotmail.com
}

Resumen

\begin{abstract}
- SPACIO PRIVILEGIADO PARA UNA PUESTA EN ESCENA DE LO POLÍTICO, LOS PROCESOS ELECTO[ rales se prestan para un juego sutil entre las apariencias y las pertenencias. Al respecto, la participación de representantes del movimiento indígena colombiano en elecciones locales regionales y nacionales ha dado lugar a un fenómeno paradójico a primera vista: la afirmación de la indianidad en contextos extracomunitarios. En efecto, si bien la participación indígena en los procesos electorales muestra su voluntad de apertura e inserción dentro de una dinámica política nacional, se constituye también en un medio para reivindicar elementos considerados específicamente indígenas que se adhieren a aspectos más clásicos del ejercicio político. El artículo intenta develar los discursos y las estrategias que acompañan dichas prácticas entre los miembros de las organizaciones político-electorales indígenas.

PALABRAS CLAVES: apariencias, pertenencias, movimiento indígena, elecciones, organizaciones indígenas, AICO, ASI, MIC.

Abstract

S PRIVILEGED SPACES FOR ENACTING THE POLITICAL, ELECTORAL PROCESSES ALLOW THE SUBTLEA slippage between appearances and membership to take place. The participation of representatives from the Colombian indigenous movement in local, regional and national elections has produced what at first sight appears to be a paradoxical phenomenon: the affirmation of "indianness" in contexts outside the community. In effect, although indigenous participation in electoral processes shows their openness and insertion within the dynamics of national politics, it also constitutes a medium for re-vindicating those elements considered to be "specifically indigenous" related to the more "classical" aspects of political action. The article examines the discourses and strategies accompanying such practices between the members of the indigenous politico-electoral organizations.
\end{abstract}

KEY WORDS: appearances, membership, indigenous movement, elections, indigenous organizations AICO, ASI, MIC.

Revista Colombiana de Antropología

Volumen 38, enero-diciembre 2002, pp. I6I-I88 


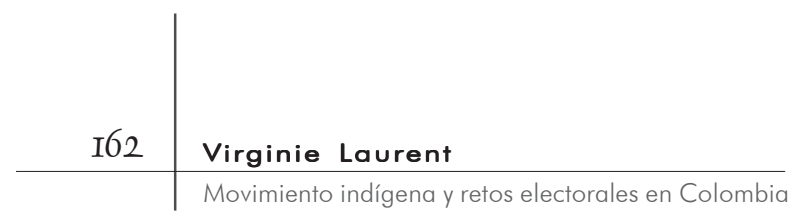

\section{INTRODUCCIÓN *}

[ n COLOMBIA, DESPuÉs DEL NACIMIENTO DE ORGANIZACIONES REgIO- nales de defensa de las peticiones de las poblaciones indíge- nas en los años 1970 -derecho a la tierra y a la identidad,

* Este artículo se inscribe en una serie de discusiones sostenidas dentro del Grupo de reflexiones sobre las pertenencias y las apariencias en las américas (GRAPPA) durante 200I-2002. Así mismo, se basa en gran parte en una investigación llevada a cabo en el marco de una tesis doctoral de sociología, realizada bajo la dirección de Christian Gros y sustentada en julio de 200I en la Universidad Sorbonne Nouvelle París III, que será publicada próximamente por el ICANH: "Communautés indiennes et espaces politiques en Colombie. Motivations, champs d'action et impacts (1990-I998)"

I. En I97I se fundó el Consejo Regional Indígena del Cauca (Cric). Pionero en Colombia, servirá de modelo en otras regiones del país en donde las organizaciones indígenas se multiplicaron poco a poco hasta la creación, en 1982, de la Organización Nacional Indígena de Colombia (Onic). No obstante, el Cric no será la única organización en el Cauca. A fines de los años 1970, un grupo de disidentes, activos principalmente alrededor del resguardo de Guambía, creó el Movimiento de los Gobernadores en Marcha, que se convirtió más tarde en el Movimiento de Autoridades Indígenas del Suroccidente.

2. Se entiende aquí por comunidad o parcialidad -indígena- a la unidad territorial y administrativa que corresponde al resguardo; por extensión, también a sus habitantes.

3. Cuando hago alusión a candidatos, listas, campañas electorales, programas, estrategias o discursos políiticos indígenas me refiero principalmente a estas tres organizaciones. Durante la constituyente, la Onic defendió los intereses de las comunidades indígenas del país al lado de un miembro de un Movimiento de Autoridades Indígenas de Colombia (AICO), creado a escala nacional en I990 sobre las bases del Movimiento de Autoridades Indígenas del Suroccidente. No obstante, cuando la Onic se reunió en I99I para elegir el candidato destinado a representarla en el senado $\$$ toma en consideración por parte del estado-, y de su extensión en todo el país durante la década de $1980^{1}$, en la de I990 la constitución de I99I confirmó el reconocimiento de sus reivindicaciones y es un momentoclave para su inserción en la escena electoral. El recurso al sufragio universal para la elección de alcaldes y gobernadores -ley II de I986, de reforma municipal; artículo 260 de la constitución política-, y la creación de una circunscripción especial para asegurar la presencia de dos representantes de los indígenas en el senado -artículo I7i de la constitución-, fomentaron de inmediato la multiplicación de las candidaturas indias. Desde entonces, sobre la base de proyectos políticos que dicen fundarse en la indianidad, las comunidades $^{2}$ indígenas afirman su voluntad de participar en los órganos de representación de la nación por medio de fuerzas que, nacidas del movimiento indígena, buscan defender, ante todo -y entre otros-, sus propios intereses. Fuerzas tales como el Movimiento de Autoridades Indígenas de Colombia (AICO), la Alianza Social Indígena (ASI) y el Movimiento Indígena Colombiano (MIC) han participado desde esa época en la actividad electoral local, regional y nacional ${ }^{3}$. 


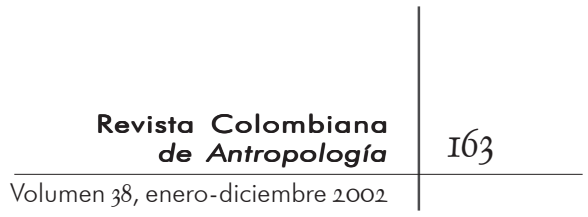

Especialmente propicios para un juego sutil entre apariencias y pertenencias, espacio privilegiado para una puesta en escena de lo político, los procesos electorales se prestan para ires y venires permanentes entre lo que parece ser-por medio de lo que se dice y se hace, de lo que se ve y se oye, de lo que se da a ver y a oír, del campo de las apariencias- y lo que supuestamente es -la identidad o, más bien, los procesos de identificación, construidos sobre la base de pertenencias múltiples, de índole familiar, política, regional, nacional, étnica, religiosa,

- durante el periodo I99I-I994, aparecieron dos orientaciones. Mientras que una parte de los participantes -mayoritaria-, compuesta por las organizaciones de las tierras bajas de país, se expresaba a favor de un ingano del departamento de Putumayo, los delegados de la zona andina se opusieron a esa elección y prefirieron dar forma a una fuerza política independiente, la Alianza Social Indígena (ASI). En respuesta a estos desacuerdos, la Onic decidió renunciar a toda participación electoral, absteniéndose así de prestarle apoyo oficial a uno $u$ otro de los sectores indígenas en competición. Sintiéndose abandonados por la organización, los militantes de las regiones de la amazonia y la orinoquia fundaron su partido, el Movimiento Indígena Colombiano (MIC). A raíz del fracaso de su principal líder después de las elecciones parlamentarias de I998, este movimiento perdió su personería jurídica. no exclusivas y no necesariamente contradictorias-. En época de elecciones, apariencias y pertenencias adquieren un peso y un significado especialmente fuertes al mismo tiempo que demuestran una maleabilidad excepcional dado lo que está en juego con ellas: el acceso de algunos al poder sobre la base de un proceso de selección -las eleccionesconsiderado racional -pues está lejos de las prácticas de brujería y otros métodos de adivinanza-, privado de discriminación -en la medida en que funciona a partir del sufragio universal directo- y cuyo resultado depende en gran parte de la fuerza de los candidatos para convencer al electorado.

Tal fenómeno incita a interrogarse sobre la existencia de posibles modos indígenas de participar en las elecciones, y lleva a acercarse de manera general a la relación entre identidades y retos políticos. ¿En qué medida las reivindicaciones y argumentos identitarios pueden dar forma a un capital político -politización de la etnicidad-? ¿Cómo puede la apertura de nuevos espacios de negociación, decisión y participación para los protagonistas étnicos en el sistema político, contribuir a fomentar la reafirmación de los particularismos -etnicización de lo político-? ¿Cómo llegar, sobre todo, al difícil equilibrio para ser, a la vez, suficientemente pero no demasiado indígena para motivar el respaldo de los votantes con el fin de acceder al poder? ¿Cómo, para ello, se escoge a los candidatos? ¿Quiénes son y cuál es su trayectoria? ¿A quién se dirigen y en qué términos? ¿Cómo puede ser perceptible su 


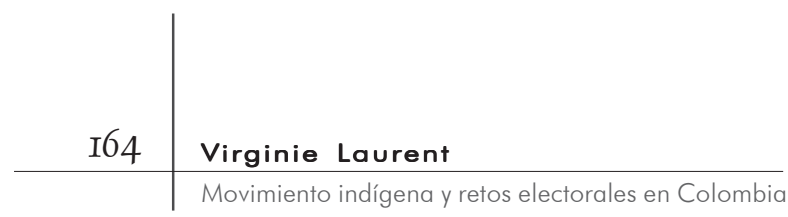

diferencia? ¿En qué medida se trata de candidatos como los demás? Porque desde su inserción en las elecciones el movimiento indígena colombiano enfrenta un nuevo reto: reunir un electorado más amplio en torno a una causa fundada, a priori, sobre una identidad que se reivindica como específica.

$\mathrm{Al}$ respecto, la contribución de los candidatos del movimiento indígena al agite electoral y el papel que han desempeñado en algunos casos en cuanto elegidos han dado lugar, con frecuencia, a un fenómeno que parece paradójico a primera vista: la afirmación de su indianidad en un contexto extracomunitario. En efecto, la movilización electoral indígena refleja, por un lado, una voluntad de apertura e inserción dentro de una dinámica política de dimensión nacional. Sin embargo, por otro revela también, en numerosas situaciones, una serie de personalidades, discursos o estrategias por medio de los cuales elementos reivindicados o considerados como más específicamente indígenas se suman a otros aspectos, modernos o más clásicos, del ejercicio político. Este artículo intenta desvelar dichas prácticas entre los miembros de las organizaciones político-electorales indígenas.

\section{SELECCIÓN DE CANDidATOS:} POSICIONES OFICIALES, TRATOS SECRETOS, MEDIACIONES DIVINAS

\footnotetext{
| NO DE LOS ASPECTOS MÁS LLAMATIVOS DEL “APRENDIZAJE DE LA POlítica moderna" ${ }^{4}$ por parte de las organizaciones indígenas en Colombia lo constituye, sin duda, la multiplicación de asambleas de toda clase realizadas en los últimos años, sobre todo en los ámbitos nacional o regional, aunque también, a veces, locales. De unas elecciones a otras ha habido muchos encuentros, congresos y otras convenciones políticas con el doble fin de evaluar el trabajo de los elegidos del movimiento indígena y designar a los futuros aspirantes a cargos públicos. A menudo espaciadas en el tiempo, por lo general dichas reuniones dieron lugar a varios meses de reflexiones a

4. Estos términos los tomo prestados de Roberto Santana, 1992: 153, quien habla de "I'apprentissage de la politique moderne" por parte de los indígenas de partir de un esquema ordenado según un ritmo preciso. En primer lugar, con la llegada de la fecha de las elecciones empieza a pensarse en la escogencia
} Ecuador. 


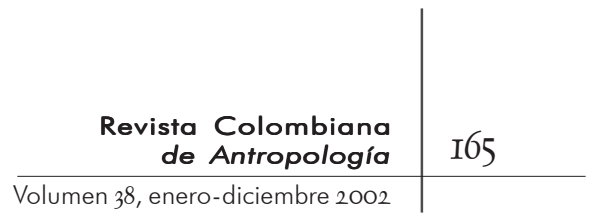

de posibles candidatos. De cierta manera, se trata de un momento previo a la selección pública de los aspirantes; selección pública que se concreta mediante el consenso -o el voto- entre representantes de las organizaciones político-comunitarias y político-electorales indígenas ${ }^{5}$, y constituye la segunda fase del proceso. Sigue, por último, la campaña electoral propiamente dicha, durante la cual, acompañado por los suyos, el candidato debe saber convencer a su electorado.

Estas deliberaciones preliminares tienen la particularidad de llevarse a cabo, si no en las comunidades indígenas, por lo menos, oficialmente hablando, con su consentimiento. El hecho de ser escogido por la comunidad es, en efecto, una de las primeras condiciones impuestas a los aspirantes a una candidatura en representación de las organizaciones AICO, ASI y MIC ${ }^{6}$ Más allá de esta modalidad, que al parecer se utilizó para todo tipo de elecciones, hay otro aspecto que puede tener un peso decisivo en la selección de un candidato: el conocimiento que tenga del mundo blanco -asociado con la idea de mejor educación, preparación y capacitación-, calidad que se requiere para pretender asumir las nuevas funciones políticas que incumben a los líderes del movimiento indígena pero también con el fin de movilizar un electorado potencial compuesto no sólo de votantes indígenas.

Sobre este punto puede señalarse que cierta jerarquía entre los candidatos es perceptible, según el tipo de corporación a la cual esperan acceder. Por supuesto, las expectativas van a la par con la importancia de la función. En el ámbito local el voto tiende a responder a preocupaciones más concretas del elector, que a menudo conoce personalmente a los candidatos y espera del elegido que contribuya a mejorar su vida cotidiana por medio de toda clase de transacciones electorales, inclusive de naturaleza puramente material: un voto contra dinero, un servicio, un empleo, etcétera. Cuando se trata de respaldar a un candidato al senado lo que está en juego no es sólo el futuro

5. Para facilitar el análisis he recurrido a una redefinición terminológica. Por organizaciones comunitarias o político-comunitarias entiendo a las que se reivindican como fundándose ante todo en autoridades consideradas tradicionales-como los cabildos-y se proponen actuar como portavoces de las comunidades indígenas a escala local, regional o nacional; y por organizaciones políticas o políitico-electorales, a las que, además de esta función de representación, pretenden participar directamente en las corporaciones públicas, objetivo que aspiran cumplir mediante las elecciones.

6. En efecto, este tipo de argumento resalta en la serie de entrevistas realizadas, entre 1995 y 2000 , con representantes locales, regionales y nacionales de las organizaciones AICO, ASI y MIC. 
de un municipio o un departamento sino el de la nación en su conjunto. Además, a pesar de su posible popularidad, el candidato está separado por una mayor distancia de muchos sus electores -por lo menos físicamente-. Por otra parte, los objetivos que persigue, y que se piensan a más largo plazo, se inspiran en orientaciones más generales definidas a escala nacional por la organización que representa. En cambio, la simbólica que emana de él puede generar cierta simpatía por parte de electores anónimos; simbólica que, en el caso de los candidatos del movimiento indígena, se basa principalmente en una combinación desconocida que de pronto puede significar la clave del éxito electoral: proyectos políticos alternativos defendidos por actores ausentes hasta entonces de la escena electoral y, por tanto, libres de sospecha en cuanto a corrupción, clientelismo, etcétera, al contrario de los candidatos de los partidos tradicionales.

En términos generales, los candidatos a las alcaldías y los concejos municipales se designan localmente, mientras que los aspirantes a las asambleas departamentales, las gobernaciones y la cámara de representantes se proponen en reuniones regionales. Por último, los futuros senadores se seleccionan durante encuentros de carácter nacional. Varios meses antes de las elecciones, los delegados locales, regionales y nacionales de las organizaciones indígenas llegan a numerosos acuerdos con el objetivo de facilitar apoyos recíprocos entre ellos. Aunque no es posible descartar del todo los cambios de última hora, puesto que las fechas de las elecciones no siempre coinciden, con frecuencia candidaturas y campañas electorales indígenas a estos distintos niveles van a la par. En este sentido, los candidatos a las alcaldías, concejos municipales, asambleas departamentales y gobernaciones no dejan de recordar sus múltiples vínculos -verdaderos o circunstanciales- no sólo con sus comunidades de origen sino también con los proyectos políticos que se proponen llevar a cabo y las organizaciones que supuestamente los defienden. Así mismo, reiteran su respaldo a todos los que, como ellos, se comprometen a

7. Para tomar parte en los procesos electorales, los candidatos deben haber recibido el aval de una de las opciones políticas reconocidas por el Consejo Nacional Electoral. favor de una organización-madre para apoyar a un candidato nacional; en otros términos, el futuro senador. Como contrapartida, este último puede interceder a veces ante dicha organización para asegurar, por ejemplo, la obtención de un aval para un candidato local o departamental ${ }^{7}$. De manera que, 


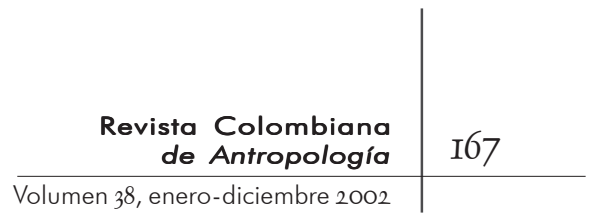

más que de candidatos individuales se trata de especies de equipos de candidatos, formados para ayudar a una u otra de las organizaciones indígenas en competición. En algunos casos, sin embargo -sobre todo localmente-, en vez de las consignas decididas en el marco de las organizaciones político-electorales se prefieren otras formas de alianzas, allí también a partir de negociaciones previas y según criterios destinados a hacer posible el apoyo mutuo en contra de la doble elección. Estas negociaciones preelectorales, autorizadas o prohibidas, se harán más que en las asambleas políticas durante intercambios personales entre representantes de las organizaciones AICO, ASI y MIC, por un lado, y los líderes regionales y locales por otro.

Entre posiciones oficiales y tratos secretos, los preparativos electorales del movimiento indígena dejan entrever poca diferencia en relación con los de cualquier otro tipo de partido político. En algunas circunstancias, sin embargo, sí son más originales, haciendo alusión, a la vez, a la idea de una especificidad y de un regreso a los orígenes. En ciertas oportunidades, en efecto, las campañas electorales toman un rumbo muy distinto y algo fuera de lo común -por lo menos desconocido por parte de los partidos tradicionales- por haberse fundado en la realización de rituales bajo la responsabilidad de chamanes y haber adquirido un carácter sagrado. Así, a veces, se recurre a los mamos, te' walas y 8. Al respecto pueden mencionarse las palabras de un líder kogui de la Sierra Nevada de Santa Marta: "Los koguis no votamos por Chucho Piñacué, porque sabíamos (...) los mamos dijeron que no iba a salir en el senado de la república, entonces por eso (...) Nosotros, antes de votar, tenemos que hablar con los mamos, quién es que vamos a ayudar entonces los mamos ordenan que hay que hacer con fulano (...). Entonces así es que nosotros hacemos elecciones por acá. Nosotros votamos por Samper, decían que sí va a ser presidente pero de pronto va a tener problema. Antiguamente, hace como 50,60 años, sí lo mandaba el colono: 'Bueno, votan por ellos, vayan', y ahora no. Todos vienen a buscar, siguen viniendo, sí, para buscar. Pero no, ahora no salimos, ahora menos" (Maruámake, mayo de I096). Sobre este mismo asunto, véase también el estudio más detallado de la campaña electoral realizada en el municipio de Páez-Belalcázar (Cauca) con motivo de las elecciones municipales de I997, en Laurent, (200I).

otros médicos tradicionales para que pongan su conocimiento ancestral al servicio de la causa política-electoral, ayuden a la elección de candidatos o, incluso, para que expliquen las posibles victorias o derrotas ${ }^{8}$. 


\section{Políticos indígenas: PERFILES Y TRAYECTORIAS}

ON LA ENTRADA DEL MOVIMIENTO INDÍGENA EN EL UNIVERSO ELECTOral, algunas personalidades de las organizaciones AICO, ASI y MIC se han destacado por haber adquirido visibilidad creciente en la sociedad colombiana. Figuras nuevas a veces, con una presencia más antigua en el marco de las reivindicaciones indígenas o, de manera más general, de la lucha popular; y otras cuyo transcurso ha permitido que sean reconocidas como elegidas en sus comunidades y organizaciones, antes -y con el finde pretender serlo en la escena electoral. Figuras, en fin, que a menudo han sido centrales en contactos paralelos entre mundos indígenas y sociedad nacional y que, en este aspecto, se han caracterizado por su papel de intermediarios entre las fuerzas políticas indígenas y sus posibles electores.

\section{Los nuevos jefes}

F NTRE LOS PERSONAJES PRINCIPALES DE LA HISTORIA POLÍTICA RECIENTE $\sqcup$ del movimiento indígena se distingue un primer grupo, compuesto por quienes pueden llamarse los nuevos jefes indios (Chaumeil, 1990). Por ello se entiende el conjunto de los líderes indígenas que debido a su inserción en la política nacional han obtenido cierto reconocimiento en el marco del movimiento indígena y, también, en la opinión pública. El papel de estos dirigentes nuevos es desconocido, en la medida en que su prestigio nacional se origina en formas de participación política hasta hace unos años poco conocidas por el movimiento indio colombiano, en otras palabras, las elecciones. Sin embargo, y con algunas pocas excepciones, estos jefes por lo general ya tienen experiencia previa, por haber dado prueba de sus aptitudes en el marco de organizaciones indígenas de tipo comunitario locales, regionales o nacionales.

Mientras que todos los representantes del movimiento indígena que accedieron al congreso entre I99I y 2002 son oriundos de comunidades indígenas del país, entre los elegidos local o regionalmente hay numerosos no indios. Así mismo, la mayoría de los indígenas elegidos que llegan o aspiran al senado se caracterizan por haber ocupado puestos de responsabilidad en sus comunidades o ante las 


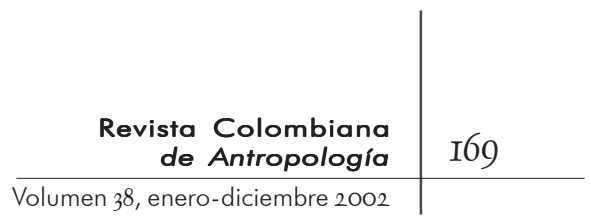

organizaciones indígenas de sus departamentos; además, muchas veces han tenido una fuerte actividad en estos dos ámbitos. Caso contrario es el de quienes aspiran a órganos legislativos o ejecutivos municipales o departamentales, que no tienen necesariamente un pasado al lado del movimiento indígena. Cuando salen elegidos, deben este éxito, ante todo, a un trabajo previo en el marco de diversas organizaciones indígenas y campesinas o sindicales, rurales o urbanas. Esta heterogeneidad de los elegidos en nombre del movimiento indígena puede explicarse, entre otros aspectos, por su apertura a otros sectores de la sociedad colombiana. Tales buenas intenciones, sin embargo, pueden volverse difíciles de manejar en la medida en que, en algunos casos, la voluntad de participar en elecciones -y la necesidad de tener el aval de una organización reconocida por el Consejo Nacional Electoral-, va mucho más allá de cualquier otra consideración.

Por otro lado, el hecho de que las organizaciones indígenas opten por proponer candidatos indígenas para representarlas en el senado refleja, sin duda, el nuevo peso de la indianidad en el escenario electoral: antes rechazada y concebida de manera negativa, hoy revalorizada y reivindicada en cuanto argumento de movilización, en especial en los periodos electorales. En este sentido es elocuente la candidatura de Floro Alberto Tunubalá a la gobernación de Cauca para las elecciones de octubre de 2000: después de varias reuniones y deliberaciones fue escogido para representar a un bloque social alternativo, multiétnico y heterogéneo -compuesto por las distintas organizaciones indígenas y múltiples agrupaciones cívicas del departamento-, mientras fueron descartados los nombres de otros líderes populares, que también habían sido propuestos inicialmente. Las razones para justificar tal preselección pueden estar relacionadas, en parte, con la experiencia del candidato en cuestión, sobre todo por su calidad de ex senador (véase más adelante). No obstante, es muy posible que se justificaran también por el impacto que, se esperaba, tendría un candidato indígena -guambiano- en un departamento marcado aún por la presencia de una elite local fuertemente antiindios. Por tanto, el símbolo por sí sólo podía llamar la atención; y, de hecho, tuvo sus consecuencias, dado que dicho candidato ganó las elecciones ${ }^{9}$.

9. Puede anotarse una excepción a esta regla, que parece darle la prioridad a aspirantes indígenas cuando se trata de acceder a puestos especialmente estratégicos: el caso de Antanas Mockus, que por primera vez significó la elección de un candidato a la alcaldía de Bogotá inscrito con 


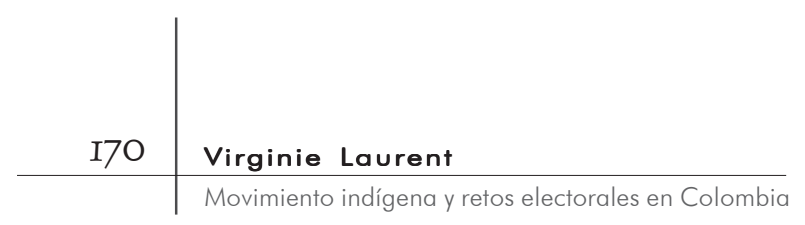

\section{Congresistas indígenas: protagonistas centrales}

I NDISCUTIBLEMENTE, ENTRE LOS NUEVOS PROTAGONISTAS DE LA VIDA política colombiana los congresistas indígenas y, en particular, los senadores, son los que cumplen el papel principal y gozan de más popularidad. Más allá de ciertos elementos comunes a todos -haber nacido en comunidades indígenas, haber participado en la creación de organizaciones destinadas a representarlas y haberse propuesto acceder a la escena electoral en nombre de fuerzas que dicen defender sus intereses- la trayectoria personal de estos líderes es variada ${ }^{10}$.

Entre los candidatos del movimiento indígena elegidos en el

$\varpi$ el aval de una organización políitica creada a raíz del movimiento indígena, la Alianza Social Indígena. Sin embargo, este fenómeno inesperado debe ser interpretado con matices. Hay que recordar, primero, que Mockus se vinculó a la Alianza Social Indígena después de que el Consejo Nacional Electoral le negó el derecho a tomar parte en las elecciones a nombre de otra fuerza política igualmente reivindicada como alternativa y de la cual él es uno de los principales voceros: el llamado Partido Visionario. Además, este candidato, fuera de las normas desde hace varios años, dispone de mucha notoriedad a escala nacional; en este sentido, la perspectiva -lograda- de su elección no podía sino serle favorable a la ASI, acompañándose entre otros efectos de un choque publicitario para esta última.

IO. Las informaciones y datos expuestos a continuación han sido recopilados durante entrevistas personales con Lorenzo Muelas (Silvia, Cauca, 2 de mayo de 1999); Anatolio Quirá (Puracé, Cauca, 23 de abril de 1999); Floro Alberto Tunubalá (Silvia, Cauca, I3 de abril de I999); Gabriel Muyuy (Bogotá, I de junio de 1999); Francisco Rojas Birry (Bogotá, I3 de mayo de 1999); Jesús Enrique Piñacué (Bogotá, I5 de octubre de I998); Martín Tengana (Bogotá, Io de diciembre de I998); Jhony Aparicio Ramírez (Bogotá, I3 de mayo de 1999); y Leonardo Caicedo (Bogotá, I3 de mayo de 1999). ámbito nacional pueden mencionarse, en primer lugar, los más antiguos: Lorenzo Muelas y Anatolio Quirá, quienes participaron en la lucha indígena de los años I970 y son oriundos de las tierras altas del departamento del Cauca -aun cuando nativos de distintas comunidades, uno coconuco y otro guambiano-. Los dos participaron en la experiencia del Cric antes de que sus caminos se separaran a principios de los años 1980, en el momento de la constitución progresiva del Movimiento de los Gobernadores en Marcha y luego del Movimiento de Autoridades del Suroccidente. Dedicados al trabajo de la tierra desde su infancia, enfrentados directamente a la exigüidad de los territorios y testigos en su juventud de la persistencia de la práctica del terraje, estos líderes se destacaron por haberse insertado tarde y, a la vez, por la puerta grande en la escena política nacional, gracias, sobre todo, a su labor de organización de las comunidades. Aunque sus estudios no fueron más allá de la escuela primaria, Lorenzo Muelas fue elegido primero miembro de la asamblea nacional constituyente en I990 y luego senador, en 1994; por su parte, Anatolio Quirá 


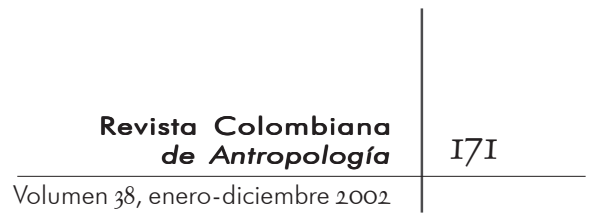

accedió a una curul en el senado en I99I, después de haber sido presidente de la Organización Nacional Indígena de Colombia (Onic) entre 1987 y I990. A pesar de todo, para estos dos hombres la prueba de la escena política nacional sólo será momentánea. Después de ese paréntesis, para ellos se tratará, antes que nada, de volver a sus regiones y actividades de origen en las comunidades, aunque más tarde se dejarán tentar de nuevo por las urnas, sin éxito: en las elecciones municipales de 2000, Anatolio Quirá fue candidato a la alcaldía de Coconuco, y en 2002 Lorenzo Muelas aspiró a una curul en el senado.

Aparte de estas excepciones, la mayoría de los demás representantes del movimiento indígena que alcanzaron el congreso o que pretendieron hacerlo son mucho más jóvenes, entre ellos los senadores Floro Alberto Tunubalá, Gabriel Muyuy, Jesús Enrique Piñacué, Francisco Rojas Birry y Martín Tengana, y los representantes a la cámara José Narciso Jamioy, Leonardo Caicedo y Jhony Aparicio Ramírez ${ }^{11}$. Estos últimos se caracterizan, en efecto, por haber tenido sólo treinta o cuarenta años en el momento de su elección ${ }^{12}$. También nativos de comunidades indígenas y allegados a líderes -o a familias de líderes-que han ejercido una función de autoridad tradicional a escala comunitaria o han participado en la construcción de las organizaciones indígenas regionales o nacionales, estos elegidos de la segunda generación sucedieron poco a poco a los mayores en los cargos de representación nacional, después de haber trabajado muchas veces regional o localmente o luego de otras trayectorias.

En términos generales, varios factores contribuyeron a favorecer su socialización e integración, por ejemplo, el acceso a la educación nacional y el paso, voluntario o impuesto, por los bancos de la iglesia -educación e iglesia están asociadas a menudo-. Las inclinaciones por la vida religiosa fueron numerosas entre estos líderes, así como

II. Floro Alberto Tunubalá y Gabriel Muyuy fueron elegidos senadores para el periodo I99I-I994. En 1994, Muyuy fue reelegido, al lado de Jesús Enrique Piñacué, Francisco Rojas Birry y Martín Tengana. Jesús Enrique Piñacué y Francisco Rojas Birry, a su vez, fueron reelegidos en 2002. Por su parte, José Narciso Jamioy, Leonardo Caicedo y Jhony Aparicio Ramírez fueron elegidos a la cámara de representantes, el primero en I99I y los otros dos en 1998.

I2. En algunos casos, la juventud de los senadores tuvo efectos perversos. A raíz de las elecciones parlamentarias de 1998, Gabriel Muyuy presentó una denuncia ante el Consejo de Estado contra Martín Tenganá, argumentando: "[e]l ciudadano Martín Efraín Tenganá no tenía las calidades exigidas por el artículo 172 de la Constitución Política de Colombia, al no contar con los 30 años que aquella impone como uno de los requisitos, pues sólo tenía 20 años, 3 meses y 20 días de edad [en el momento de las elecciones]" (Sánchez, s. f.). Por esa razón, Tenganá debió renunciar a su curul. 
las vocaciones eclesiásticas, finalmente abandonadas, como las de Gabriel Muyuy, Jesús Enrique Piñacué o Leonardo Caicedo. A pesar de ello, según las declaraciones de estos ex seminaristas, la actividad realizada en el seno del movimiento indio se acercaría al sacerdocio en la medida en que, en un caso como en el otro, tiene por objeto estar al servicio de la gente. La escuela, el colegio, la universidad o el internado -a veces bajo la tutela de la iglesia, otras veces de laicos- se constituyeron también en lugares de encuentros importantes: con los otros para los cuales uno es diferente, y con los que, como uno, también son diferentes.

Esos lugares, además, abrieron el camino para aprender a leer y escribir, para acceder a un saber hasta entonces mal o poco conocido porque era ajeno al ámbito comunitario pero tanto más valioso cuanto que es una de las claves principales del intercambio con la sociedad no india, sobre todo porque cuando se asocia a la experiencia comunitaria representa una riqueza suplementaria para quien lo posee. Lugares a partir de los cuales estos líderes indígenas pudieron adquirir conocimientos en cuanto alumnos y, en algunas circunstancias, transmitirlos como profesores. Lugares que, finalmente, por todas estas razones han podido favorecer también la circulación de la información, por ejemplo la relativa a las condiciones de vida de las poblaciones indias, a los procesos de organización o a las aspiraciones electorales. Espacios y circunstancias que, por tanto, han sido propicios para la evolución del estatus personal y de una categoría -la de indígenas- que en la mayoría de los casos es reivindicada pero que en ciertas ocasiones es rechazada o renegada -por ejemplo vistiéndose como los blancos- porque el hecho de ser asimilado a ella es sinónimo de inferioridad. Además de la iglesia y la escuela debe destacarse también el papel significativo que desempeñaron en algunas trayectorias personales algunas instituciones estatales como el Instituto Colombiano para la Reforma Agraria (Incora), el Plan Nacional de Rehabilitación (PNR), la Red de Solidaridad Social, la oficina de asuntos indígenas del Ministerio del Interior o las oficinas de planeación departamental; e, incluso, de la Asociación Nacional de Usuarios Campesinos (Anuc), creada por el gobierno nacional.

Entre estos indígenas elegidos pudo observarse que la toma de conciencia de su diferencia pasó generalmente por la mirada de los demás y que se percibió a partir del racismo expresado en 


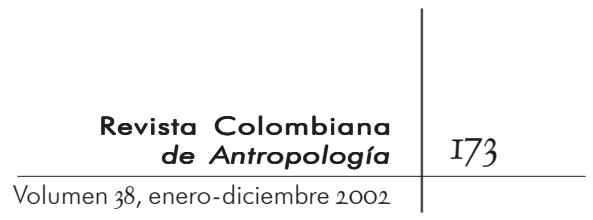

contra suya. A este respecto, insistieron en un sentimiento de injusticia vivido durante la niñez o la adolescencia. Por eso, para varios de ellos parece haberse tratado, hasta cierto punto, de buscar una revancha ante una situación de desigualdad de hecho, independiente de su voluntad: en la escuela para llegar a ser el mejor alumno; entre grupos de estudiantes para compartir una vivencia similar; en organizaciones indígenas, creadas precisamente con el objetivo de defender intereses y derechos negados; y en la escena electoral, quizá el lugar supremo de reconocimiento para los que parecían olvidados hasta entonces.

Sin embargo, más allá de bases comunes se destaca la diversidad de las trayectorias. De las tierras altas a las tierras bajas los orígenes geográficos y étnicos de los miembros de esta nueva elite política son múltiples, lo mismo que sus experiencias en las organizaciones indígenas. Guambiano y nasa de Cauca, respectivamente, Floro Alberto Tunubalá y Jesús Enrique Piñacué participaron en el Consejo Regional Indígena del Cauca, aunque con un intervalo de cerca de diez años. El primero contribuyó durante un tiempo al desarrollo de la organización en los años I970, antes de retirarse de ella -cuando se creó el Movimiento de Autoridades del Suroccidente- y de convertirse en uno de los principales representantes del Movimiento de Autoridades de Colombia. Elegido senador en I99I, es el primer gobernador -de departamento-indígena de la historia de Colombia. El segundo, por su parte, ha llegado al senado en dos periodos (1998 y 2002) en representación de la Alianza Social Indígena, después de haber sido tesorero, vicepresidente y presidente del Cric entre 1988 y 1997.

Por otro lado, el ingano Gabriel Muyuy y el kamsá José Narciso Jamioy, originarios de Putumayo, siguieron también dos vías paralelas: el uno accedió al senado en nombre del MIC en I99I y en 1994, después de haber contribuido a las actividades de la Onic y, en especial, a la formación de una organización regional -Musu-Runacuna (Hombres Nuevos)- en su departamento; el otro fue el primer representante indígena a la cámara, elegido en I99I en representación del Movimiento de Autoridades. Embera de Chocó, Francisco Rojas Birry también pasó por la Onic como miembro de la Organización Indígena de Antioquia- para insertarse en la escena política-electoral en el momento de la asamblea nacional constituyente, antes de ser senador por la ASI en I998. También en la época de la constituyente fue que 


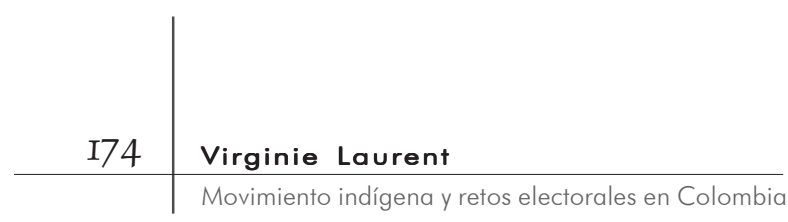

Martín Tenganá, pasto de Nariño y primer renglón de la lista del Movimiento de Autoridades de Colombia elegido en el senado en 1998, se acercó a las reivindicaciones indígenas. Por último, Leonardo Caicedo, wanano del Vaupés, fue representante de la Alianza Social Indígena en la cámara entre 1998 y 2002, después de haber llegado a saber de la existencia de la organización apenas unos meses antes, por medio de Francisco Rojas Birry, así como su colega Jhony Aparicio Ramírez, nacido en el departamento de Guainía, de madre sikuani y padre boyacense.

\section{Líderes regionales: de la comunidad al movimiento cívico}

A DEMÁs DE LOS POCOS ELEGIDOS PRIVILEGIADOS CON TRAYECTORIAS Y $A$ papeles (re)conocidos a escala nacional, a lo largo y ancho del país un número considerable de representantes de las organizaciones políticas indígenas accedió a las alcaldías, consejos municipales y asambleas departamentales. En términos generales, ellos también llegaron a esos cargos públicos después de una experiencia previa en diversas asociaciones -todas reivindicadas como populares-, y cuando asumieron sus funciones tenían varios años de práctica con el trabajo de base. Enmarcadas principalmente en el ámbito local -o a veces regional-, sus trayectorias son también muy variadas ${ }^{13}$.

Algunos pueden ser identificados a partir de su pertenencia étnica, así como por la naturaleza de su relación con el mundo comunitario. En este caso se trata de personas que, vinculadas casi permanentemente a su comunidad de origen, se califican comúnmente de indígenas o, de manera más precisa, se autode-

I3. Por razones prácticas fue imposible efectuar una encuesta exhaustiva con todos los candidatos elegidos regional y localmente en representación de las organizaciones indígenas, pues eran muy numerosos. A manera de ejemplo, sin embargo, se intentó dar cuenta del camino seguido por algunos de estos líderes, en su mayoría de los departamentos de Cauca y Vichada, escogidos para la realización de estudio de casos para mi investigación doctoral. nominan aún como miembros de una etnia particular -nasa, guambiano, wayuu, embera, zenú, etcétera-. Por esta misma razón, con independencia de su participación en las elecciones, estos elegidos pretenden ser asimilados, ante todo, a comuneros como los demás y dicen mantener una relación constante con los representantes del poder comunitario así como con la lla- 


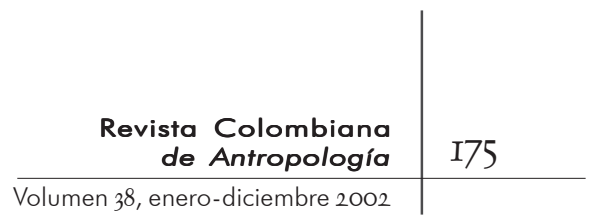

mada autoridad tradicional -en especial con los miembros del cabildo y, a veces también, con los chamanes-. Paralela a la importancia que conceden a sus vínculos comunitarios, muchos de esos líderes demostraron de antemano un compromiso personal con las organizaciones indígenas del país, locales, regionales o nacionales. En muchos casos también, antes de involucrarse en el escenario más amplio de las elecciones, dieron sus primeros pasos en esas asociaciones de tipo político-comunitario, con las que mantienen una relación estrecha.

A su lado, otros líderes representaron al movimiento indígena en el campo electoral, después de haber sido parte de otras organizaciones -campesinas, cívicas, obreras, estudiantiles, etcétera- que no se fundaban específicamente sobre la indianidad. En su mayoría no indígenas, se destacan por haber trabajado poco con esas comunidades y, más bien, por haber participado en movimientos sociopolíticos locales de todo tipo, alternativos o independientes. Por otro lado, más allá de su nuevo estatus en cuanto miembros o representantes de organizaciones políticas indígenas, muchos de ellos no dejan de afirmar sus vínculos, sobre todo con las asociaciones en el seno de las cuales se inscribieron al principio de su actividad militante.

Por último, debe mencionarse una tercera serie de perfiles entre los elegidos para representar a las comunidades indígenas del país en el ámbito local que, paradójicamente, se caracterizan por su alejamiento del movimiento indígena. Indígenas y no, se distinguen sobre todo por haber sido intermediarios electorales de organizaciones y movimientos políticos cercanos a los partidos liberal y conservador. A menudo también, su simpatía y solidaridad en relación con las fuerzas AICO, ASI o MIC parecen haber nacido de manera un tanto espontánea y haber desaparecido igual de rápido después de las elecciones. Para muchos de ellos, en efecto, no existía ningún vínculo directo con las organizaciones indígenas, comunitarias o electorales, hasta la incursión del movimiento indio en la escena política a principios de los años I99o. El aparente interés de estos elegidos por una supuesta causa alternativa -indígena, cívica, popular-parece haber correspondido sobre todo a aspiraciones personales o a la necesidad de obtener un aval por parte de las organizaciones que disponían de personería jurídica, con el fin de participar en las elecciones, más que a una motivación verdadera para construir una nueva opción política. Por esas mismas razones, muchas veces recibieron reproches 
por parte de las organizaciones políticas indígenas, con las que no mantenían contacto alguno después de las elecciones.

\title{
Prácticas electorales: INTERACCIÓN ENTRE DOS MUNDOS
}

\begin{abstract}
C ON LA TRANSFORMACIÓN DE LOS TÉRMINOS, FORMAS, LUGARES Y REpresentaciones del poder que la acompañaron, la movilización indígena de estos últimos años revela una serie de intersecciones e interacciones permanentes entre espacios comunitarios y nacionales y modos tradicionales o modernos de hacer políti$\mathrm{ca}^{14}$. En este nuevo contexto, que refleja el carácter dinámico de las asignaciones identitarias, los procesos electorales han dado lugar a numerosos rituales, inherentes a toda actividad política (Abéles, I997), pero basados en este caso en distintos tipos de prácticas, las cuales pueden considerarse, por un lado, herencia de un modelo legado por los partidos tradicionales, y, por otro, pretenden revelar, más bien, cierta especificidad indígena.

Entre las conductas que podrían calificarse de modernas puede señalarse, por ejemplo, el recurso a gran cantidad de carteles, pasacalles y calendarios con la imagen de los candidatos del movimiento indígena, más concretamente de AICO, ASI y MIC. Este material de publicidad visual fue complementado, además, por un apoyo sonoro mediante mensajes difundidos por las emisoras de radio -principalmente locales y regionales-, que buscaba recordar las principales propuestas de acción de los candidatos e incitar al electorado a apoyarlos. En algunas ocasiones, los candidatos fueron objeto, incluso, de un tratamiento privilegiado en la prensa o la televisión. Cabe anotar, sin embargo, que no todos los numerosos candidatos a las corporaciones públicas del país fueron objeto de la misma atención ni dispusieron de medios equivalentes para la

I4. Este es uno de los puntos sobresalientes en el trabajo de investigación y observación realizado en el marco de la

I5. Entre los candidatos más mediatizados puede hacerse referencia especial a Lorenzo Muelas y Jesús Enrique Piñacué; en menor medida a Francisco Rojas Birry y Gabriel Muyuy; por último, puede realización de su campaña electoral; de nuevo es necesario establecer una primera distinción, en función del tipo de elecciones en las cuales se participó, dado que los esfuerzos más grandes se hicieron para competir por las curules del senado. Así las cosas, unos se destacaron más y fueron más populares que otros ${ }^{15}$.
\end{abstract} tesis doctoral mencionada. 


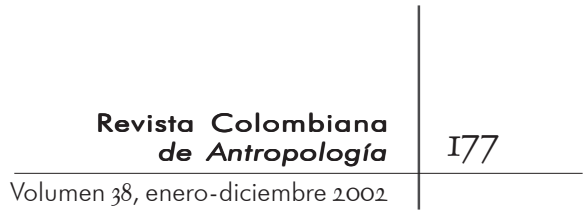

Por otro lado, todos los candidatos indígenas aspiraron a acercarse lo más posible al electorado; con este fin visitaron a sus comunidades y a veredas y barrios poblados por no indígenas, desde los pueblitos hasta las grandes ciudades; se desplazaron hacia los colegios y las universidades; y participaron en actos culturales. De

- decirse que la elegida de la ASI a la asam blea departamental de Antioquia, Eulalia Yagarí, también estuvo en la mira de los medios de comunicación, a raíz de su excelente resultado en las elecciones de octubre de 1997.

I6. No se trata de decir con ello que semejante indianidad sólo se reivindica con el objetivo de recoger votos sino de mostrar hasta qué punto puede ser utilizada en las campañas electorales. este modo estuvieron en el centro de numerosos encuentros y mítines políticos de dimensión local, regional y nacional que, sin duda alguna, constituyeron una de sus principales actividades preelectorales. Sin embargo, la particularidad de las campañas electorales indígenas reside en el hecho de que, además de procedimientos probablemente indisociables de cualesquiera de los preparativos que buscan el acceso a cargos de representación pública, estos siempre han estado acompañados de algo de indianidad, perceptible tanto en el contenido de los programas políticos como en la manera de expresarlos ${ }^{16}$.

\section{Palabras...}

T N PRIMER LUgAR PUEDEN DESTACARSE ALGUNOS DE LOS GRANDES TE$\sqcup$ mas comunes a varios candidatos indígenas: la ecología y la defensa del medio ambiente; la mayor justicia social; la instauración de una economía solidaria; y, por último, el estímulo de la interculturalidad. Así mismo, las campañas electorales indias hicieron referencia en muchos casos a unas imágenes alimentadas por la existencia supuesta de una sabiduría indígena, considerada como garante del equilibrio entre el hombre y la naturaleza, guiada por el conocimiento de los antiguos, nutrida por el respeto del compartir y reforzada por el concepto de la minga -un trabajo común para beneficios comunes-. En este sentido, afiches y programas electorales fueron elocuentes con frecuencia y en algunos aspectos parecen haberse inspirado en un modelo indio ideal, predicando la llegada de una nueva sociedad, equitativa y no violenta.

Así, por ejemplo, la alianza Navarro-Piñacué, formada en 1994 con el propósito de llegar a la presidencia y la vicepresidencia, se 
proponía no sólo hacer de la paz una prioridad y fomentar la lucha decidida en contra de la corrupción a escala nacional, sino también aplicar una política económica participativa y solidaria, cercana hasta cierto punto a la idea relativa a la repartición de las riquezas en las comunidades indígenas. El Compromiso Colombia tenía por objeto, además, apoyar a estas últimas en sus esfuerzos contra la discriminación y la segregación, con el fin de asegurar la igualdad de oportunidades para todos y hacer posible la aplicación los principios constitucionales. Por último, los candidatos de esta coalición entre la AD-Mig y la ASI pretendían velar por la protección del medio ambiente "para gobernar en armonía con la naturaleza", y "usar creativamente la biodiversidad del país" para que se respetaran los conceptos del desarrollo sostenible (Compromiso Colombia, 1994).

Con base en esta doble apuesta, fundada en el equilibrio entre mundos indígenas y no indígenas, varios líderes del movimiento indígena aspiraron al congreso por medio de una nueva alternativa a favor de la nación colombiana en su conjunto y respetuosa de las comunidades indígenas. Dentro de una Colombia que necesitaba "encontrar su camino", los candidatos indígenas aparecían como los poseedores de "la memoria”, a los cuales, por tanto, habría que dar la palabra de ahora en adelante (Alianza Social Indígena, 1994). Porque toda alternativa popular debía "surgir de la convergencia de aquellos movimientos sociales que promuevan la participación de las comunidades, la defensa de la naturaleza y consideran la vida digna como el centro de toda propuesta económica y social" (Alianza Social Indígena, 1994). Porque había que "compartir con otros movimientos el concepto de democracia, que tiene como componente fundamental la participación social desde las bases" (Alianza Social Indígena, 1994). Porque, a escala nacional, había que lograr mayores niveles de "participación ciudadana"; hacer posible la implementación de una economía adecuada con las necesidades sociales; respaldar las iniciativas a favor de la paz y la autonomía territorial; motivar una reforma agraria para las comunidades campesinas; y proteger el medio ambiente (Alianza Social Indígena, I997a; Jacanamijoy, 1997).

Municipal y departamentalmente se planteó también ese tipo de objetivos: "participación social” en cuanto a planeación, gestión y control de las actividades y los presupuestos a favor de una administración transparente; adaptación de la economía a 


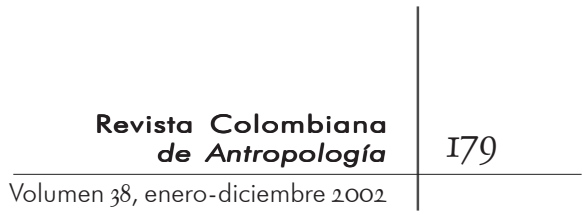

las necesidades sociales y previsión de planes de desarrollo adecuados; toma en consideración de las reivindicaciones de las comunidades indígenas; mejoramiento de sus condiciones de vida; difusión de la información relativa a los derechos humanos e indígenas; exigencia del respeto de la población civil por parte de los actores armados; y protección del medio ambiente (Bloque Social Alternativo, 2000; Jacanamijoy, I997; Movimiento Cívico Indígena Campesino, 1994).

Cuántas ambiciones podrían alcanzarse gracias a la "serenidad que Colombia necesita” (Franja Amarilla, 1997) -la serenidad, otra cualidad atribuida generalmente a los indígenas de manera estereotipada-. El éxito pasaría, además, por la igualdad de todos en un esfuerzo unívoco, dado que "la causa indígena, es igualmente la lucha de todos" (Jacanamijoy, 1997). Por tanto, sería necesario "que todos se levanten, que se llame a todos, que no haya uno ni dos entre nosotros que se quede atrás de los demás” (Alianza Social Indígena, I997a). Además, se trataría de encontrar "un alcalde para todos" y de actuar "todos juntos por” la alcaldía (Alianza Social Indígena, I997b). A este respecto, el candidato aparecería a la vez como la ilustración y el vocero de una "decisión comunitaria" (Alianza Social Indígena, 2000a). Sería el "hombre de confianza de todos" (Alianza Social Indígena, 200ob). Y, ante todo, se trataría de adelantar un trabajo comunitario: "en minga por Silvia” (Movimiento Autoridades Indígenas de Colombia, I997), “en minga por Páez” (Movimiento Indígena de Páez, 2000) y hasta "en minga por el Cauca" (Bloque Social Alternativo, 2000).

\section{... e imágenes}

A DEMÁs de Su CONTENido, las opCiOnes políticas indígenas SE Afundaron en, y dieron lugar a varias formas de expresión destinadas a reflejar su especificidad, y en ese sentido a permitir que se percibieran como distintas, alternativas, en relación con las propuestas de las demás fuerzas que participaban en las elecciones. Así como es cierto es que los candidatos indios recurren con frecuencia a las astucias modernas del mundo político mencionadas antes, también lo es que los candidatos de los partidos tradicionales se prestan para una fuerte teatralización de lo político. 


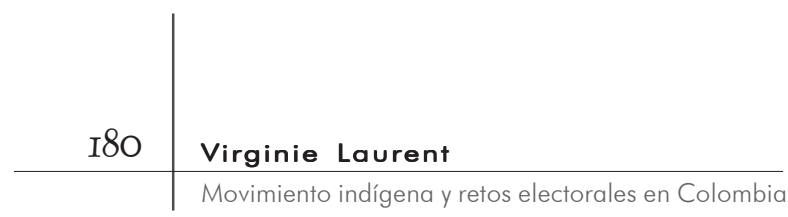

Sin embargo, en este caso debe tratarse, ante todo, de un espectáculo indígena. Es muy interesante observar cómo en esta oportunidad a los modelos clásicos de reuniones políticas se suma una serie de elementos que por la puesta en escena, el decorado, la música y las posiciones que motivan, construyen, a su vez, una "identidad distintiva" de los candidatos indígenas en cuanto tales (Abélès, 1997: 255).

Aparte de la realización de mítines de apertura y cierre de campaña en las plazas públicas, los procesos preelectorales de los indígenas se han caracterizado por un ritmo particular, que en algunos casos han podido denominarse con los términos de "chicha, chiva y chirimía”. En efecto, a veces se recurrió al bus escalera para desplazarse en caravanas hacia los resguardos o a visitas a las parcialidades, acompañadas a menudo por orquestas locales de flautas y tambores. iY a la distribución de aguardiente -cuyas virtudes en los periodos electorales son bien conocidas por los partidos tradicionales- se sustituyó -o asoció- la repartición, de por sí muy ritualizada, de la chicha, que los indígenas de todo el país también aprecian! Además, muchas veces, durante los mítines, los discursos han sido realizados en lenguas autóctonas para explicar la importancia de un voto indio para candidatos indios.

Por otra parte, en algunas ocasiones los candidatos indios reclamaron la ayuda de lo sobrenatural: en el momento de la selección de los aspirantes y durante la campaña electoral propiamente dicha, se llama a los chamanes a trabajar para cargar a los aspirantes a corporaciones públicas de buenas energías y preservarlos de las malas. En algunos casos, estos rituales, generalmente de carácter privado, adquieren una dimensión pública: el día de las elecciones parlamentarias de marzo de I998, uno de los candidatos al senado se dedicó a pedir la ayuda de los dioses en una plaza del centro de Bogotá, gesto que no escapó ni a los curiosos ni a las cámaras de televisión pero que, sin embargo, no trajo los frutos esperados. 


\begin{tabular}{r|r} 
Revista Colombiana & \\
de Antropología & I8I \\
\hline Volumen 38, enero-diciembre 2002 &
\end{tabular}

\section{Pertenencias y apariencias}

\lceil ALES EVOCACIONES DEL MUNDO INDÍGENA -Y SU EVENTUAL SACRALIzación por medio de rituales diversos- probablemente serán más útiles, y quizá necesarias, para los candidatos indios a lo largo de las campañas electorales. Como lo anota Jean François Bayart, el imaginario político es propio de toda sociedad e irreductible. Así mismo “(...) las sociedades industriales 'racionales', 'centralizadas', 'burocráticas', ‘desilusionadas', son tan imaginativas como las sociedades antiguas 'tradicionales', supuestamente dominadas por una idea mágica o religiosa del mundo” (Bayart, I996: I43). Mediante el imaginario se trata, para unos, de afirmar y hacer reconocer una identidad con el fin de motivar el apoyo a una opción político-electoral; para otros, de ser receptivos a la primera con el fin de adherir a la segunda. Por medio de los símbolos que trae consigo tanto para el elector como para el elegido potencial, el imaginario puede ser el principal puente entre estos y aquellos. De esta manera, la imagen desempeña un papel innegable a fortiori, en la medida en que llega a reemplazar lo escrito allí donde prevalece el analfabetismo (Bayart, I996: I47), y que en este sentido se presta siempre para agitar los espíritus, alimentar la reflexión y atizar los conflictos (Gruzinski, I99I: I3).

En el caso de América latina el peso de la imagen se reveló fuertemente, en especial en el momento de la conquista; cuando llegaron al continente, los españoles se dedicaron no sólo a destruir los ídolos indios sino también a distribuir gran cantidad de ilustraciones que representaban a Cristo, a los santos o a la Virgen. A partir de entonces, “[p]or razones espirituales (los imperativos de la evangelización), lingüísticas (los innumerables obstáculos planteados por las lenguas indígenas), técnicas (la difusión de la imprenta y el desarrollo del grabado), en el siglo XVI la imagen ejerció un papel notable en el descubrimiento, la conquista y la colonización del nuevo mundo" (Gruzinski, I99I). Con el paso del tiempo, sin embargo, las poblaciones reaccionaron a las imágenes por medio de procesos permanentes de reapropiación y recreación cultural, individuales y colectivos (Gruzinski, I99I: 263). Así, “[l]as imágenes cristianas habían cumplido su función inicial, habían vinculado el mundo indígena con Occidente, pero la iniciativa de los indios había llegado a sustraer el objeto del control de los que lo habían impuesto" 


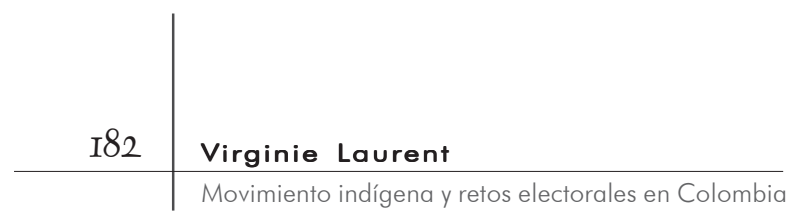

(Bayart, 1996: 49). Poco a poco, no se trató, necesariamente, de "guerra" sino, a veces, de "comunión” o de "compartir de imágenes” (Bayart, 1996: I47).

Durante la campaña electoral adelantada por los indígenas parece ejercerse un doble juego. Por un lado, los diversos emblemas cargados por los candidatos pueden significar, de alguna manera, su integración a un orden heredado de la época hispánica, y al utilizarlos los candidatos del movimiento indígena se proponen, de hecho, insertarse en un sistema político que se impuso progresivamente desde el exterior. De otro lado, sin embargo, la tendencia parece ir, en parte, en una dirección contraria. Así como en tiempos remotos lo hicieron los españoles con imágenes piadosas para convertir a los indios, hoy en día son estos los que blanden sus banderas, banderas que los reivindican como miembros de la misma "comunidad imaginada" y permiten que "los otros" también los reconozcan como tales. Así las cosas, esta vez se trata de iconvertir a los blancos!

Así mismo, según lo que afirma Bayart, el imaginario llega a materializarse inclusive -y sobre todo- en el campo político: por ejemplo mediante simbólicas tales como el cabello -y sus derivados-, las comidas o los vestidos. Por otra parte, y de nuevo según Bayart, para que el imaginario político pueda funcionar debe basarse en otras dimensiones del imaginario social: el de la familia, así como los de la creencia religiosa, el mundo de la empresa, la competición deportiva, el entorno internacional, etcétera. Porque es precisamente la intertextualidad entre las prácticas sociales -entre los actores, las épocas, los ámbitos de la sociedad- lo que, tal como una máquina, sirve para abastecer el imaginario, para "fabricar lo equívoco, y todas las emociones correspondientes: la esperanza, la alegría, la inquietud, el miedo, el odio" (Bayart, I996: I76). Paralelamente, el imaginario vendría a materializarse, incluso -y sobre todo- en el campo político, por ejemplo mediante los tres elementos que destaca Bayart como especialmente significativos debido a la fuerza de la simbólica que los rodea (Bayart, 1996). Pelo, comida y vestido, muy significativos cuando se trata del imaginario vinculado a los nuevos retos electorales del movimiento indígena. 


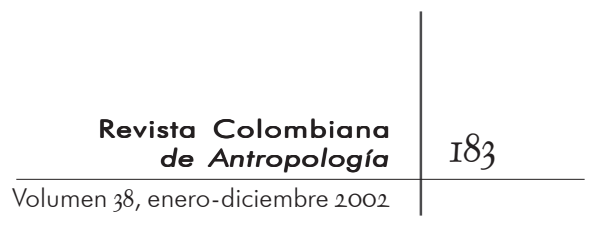

\section{El cabello}

S IENDO TRAdicionalmEnte Objeto DE MUCHA ATENCión POR PARTE $\mathcal{U}$ de los individuos en la mayoría de las sociedades, las simbólicas pilosas -barba, bigote, pelo - serían unos "actores imprevistos de la escena social” (Bayart, I996: I86-I87). Jean François Bayart da testimonio de la manera como "esta capacidad para condensar lo político que demuestra el cabello”, y la polémica que este último genera pueden ilustrarse a veces a partir de una "escena de la vida cotidiana” en Palestina:

[el] Hamas un día se indignó porque la policía de la autoridad había afeitado la barba de sus cuadros encarcelados, lo que según él constituía un asunto ‘muy serio, peor que los golpes o la tortura' (sic). El general Moussa Arafat parecía estar de acuerdo, puesto que se apresuró a desmentir: 'Me atera oír tales rumores, en el seno de la autoridad nadie comete semejantes

horrores' (Bayart, 1996: I89) ${ }^{17}$.

I7. iSin duda alguna, del bigote de Pancho Villa y Emiliano Zapata a la barba de Ernesto

Esta referencia al cabello no deja Che Guevara -y sus seguidores respectide ser significativa cuando se sabe vos-, la historia del pelo en América latina que numerosos líderes indios tienen poco tiene que envidiarle a la riqueza que demuestra en Palestina!

el cabello largo o medio largo -en todo caso, no corto-. Entre ellos, con su cabellera que no deja de recordar -quizá- la del indio Quintín Lame, Jesús Enrique Piñacué, Francisco Rojas Birry, Benjamín Jacanamijoy -candidato al senado en 1998, en nombre de la Nueva Fuerza Democrática, movimiento cercano al Partido Conservador- o también Abadio Green -presidente de la Onic entre 1993 y I998- y Gerardo Jumí -miembro de la ASI, segundo renglón de la lista de Antonio Navarro, senador elegido en 2002-; todos ellos inspiran la idea romántica de cierta rebeldía indígena y de la afirmación de una libertad tomada ante las normas establecidas. A su lado, Gabriel Muyuy optó, por su parte, por un corte tradicional indígena, más representativo de la amazonia. Así las cosas, el cabello indio remplaza la barba española. Ciertamente, en este caso la suerte del pelo no se establece mediante normas, religiosas o de otro tipo, tan estrictas como aquellas que pueden regir en Palestina. Esta vez, al contrario, se elige. El hecho de que estos personajes sean todos jóvenes seguramente no es extraño por completo a la manera como su cabello refleja su indianidad, dando de ellos una imagen más bien original y simpática que, a propósito, no es exclusiva de 


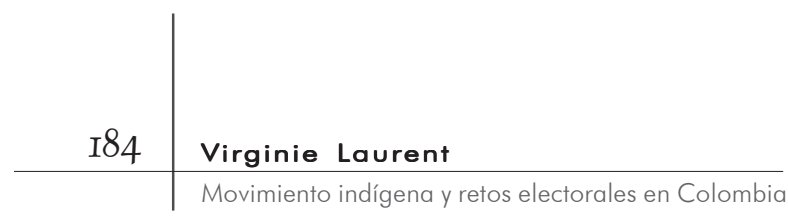

los indígenas puesto que numerosos otros jóvenes, no indios, tienen también el cabello largo. El cabello largo puede servir, además, a otra causa. Puede ayudar, por ejemplo, a la identificación de los candidatos en el tarjetón, aspecto útil en el momento del voto. No obstante, las cosas se complican a veces cuando todos, o casi todos, tienen el cabello largo. Al respecto, candidatos y militantes indígenas debían disfrutar mucho de una pequeña anécdota que repiten con gusto y habla de sí mismos: "Dijimos 'voten por el que tiene el cabello largo'. Y la gente preguntaba: ‘cuál?, si son tantos””.

\section{La comida}

Muy distinto del Cabello, La comida, según Bayart, Demuestra 1 también un fuerte poder de integración:

(...) la comida, lejos ser un simple mecanismo de consenso automático, es una instancia de negociación y, por tanto, de intermediación relativa. Puede funcionar como un procedimiento de movilización, lealtad o reconciliación (...). Así, comer juntos es una mediación recurrente de la participación política en todo lo que tiene de dinámica, compleja o, incluso, de conflictiva (...). En China los vínculos de clientela (...) se hacen y deshacen también con gran cantidad de 'comilonas y borracheras' (...), momentos elementales de la vida política de los cuales no hay que subestimar el costo económico (Bayart, I996: 19I).

Por tanto, según Bayart las prácticas culinarias contribuirían "discretamente pero de manera decisiva, al 'mantener junto' de las sociedades políticas, de su 'mundo de significado' y, por silenciosas que sean, las revoluciones culinarias trabajarían en una "homogeneización cultural que no carece de efectos políticos" (Bayart, I996: I92-I93). La circulación de los usos culinarios facilitaría recomposiciones identitarias que, a largo plazo, podrían convertirse en recomposiciones cívicas (Bayart, 1996: 194).

Aun cuando es cierto que así como en China, en Colombia y en el mundo entero durante las campañas electorales de los candidatos del movimiento indígena han estado presentes "grandes comilonas" y "grandes borracheras", estas ante todo se prestaron para dar a probar las especialidades indias. Con motivo de las visitas de los candidatos, las mujeres preparaban grandes ollas de 


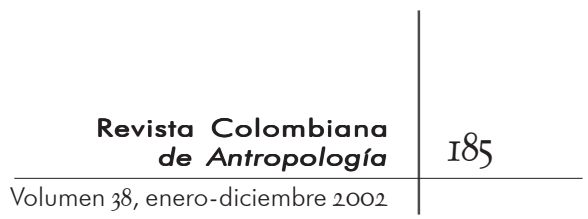

mote; los hombres, por su parte, repartían algo de tomar; y se mataron algunas vacas. Todos y cada uno, entonces, participaban en una comida colectiva, tal como las de las jornadas de trabajo comunitario u otros días festivos.

Lejos de estos banquetes comunitarios, en algunas capitales departamentales se realizaron numerosos encuentros que buscaban tomar y comer bien. iAsí, fuera del campo, en Bogotá, Medellín o Cali podría hablarse de la chicha! En diversas ocasiones, en efecto, algunos candidatos indígenas al senado participaron en actos de integración con no indígenas, que debían brindar la oportunidad, a la vez, de conocerse mejor entre distintas identidades y de reflexionar sobre preocupaciones políticas en un ambiente en el que a menudo hubo tiempo, si no para una comilona, por lo menos para alguna picadita. Puede señalarse al respecto el papel especialmente importante que desempeñaron en esta etapa los estudiantes indígenas presentes en las grandes ciudades del país. Hermanos y hermanas, primos, paisanos o simples amigos de los candidatos, ayudaron a dejar huellas de la opción indígena, dedicándose a pegar afiches en las universidades y por todas partes en las ciudades, buscando despertar así el interés de sus compañeros de estudio. Así las cosas, contribuyeron a que mucha gente, indios y no indios, asistiera a las reuniones políticas.

\section{El vestido}

D OR ÚlTIMO, A PARTIR DEL PRINCIPIO SEGÚN EL CUAL LAS SIMBÓLICAS P corporales no pueden abstraerse de la relación que mantienen con la cultura material de la sociedad en la que se inscriben, no hay relación con el cuerpo que no sea, al mismo tiempo, relación con el vestido (Bayart, I996: I95). En efecto, este último

"como todo fenómeno cultural es, al mismo tiempo, herencia e innovación: su análisis implica que sean percibidos 'en un mismo movimiento estabilidad y cambio de las apariencias'. Consiste, además, en una 'coincidencia constitutiva de lo real y lo imaginario' (...). Gracias a esta plasticidad, el vestido es un instrumento privilegiado de construcción y negociación de las identidades: de las identidades individuales (...) y, también, de las colectivas. El hábito sí hace el monje, y los actores políticos no se equivocan al respecto (...). [E]lemento constitutivo de los procesos de identificación, el 
vestido desencadena pasiones rápidamente. Está en el centro de las relaciones de amor, pero también de conflicto entre padres e hijos, entre adultos y jóvenes” (Bayart, 1996: 196-I97). Por esas mismas razones, también es "utilizado por los actores políticos, que lo usan para emitir mensajes de autoridad, proximidad u oposición, o también para pulir su estilo" (Bayart, I996: I98). Porque, "[1]a vestimenta materializa la reivindicación más o menos conciente de un 'estilo de vida' con su esteticismo, sus valores, su idea normativa de la economía moral de la urbe y, en consecuencia, en fin, su relación con la política” (Bayart, I996: 205).

En este caso también hay numerosos ejemplos para recordar cómo los trajes tradicionales de los candidatos y elegidos indígenas fueron dotados de una fuerte simbólica. Por supuesto, el uso de tales ropas es paradójico, en la medida en que en el universo precolombino muchas no existían. No obstante, reapropiadas como tales, aparecen hoy en día como signos exteriores de indianidad. Lorenzo Muelas llamó la atención desde la época de la asamblea nacional constituyente, vestido de ruana, anako y sombrero -del que orgullosamente se negó a despojarse mientras se interpretaba el himno nacional-. A su lado, Alfonso Peña -vocero del Movimiento Quintín Lame ante la constituyente- y Anatolio Quirá -senador elegido en I99I- aparecieron siempre con la cabeza cubierta de sus sombreros de paja. Más tarde, los capizallos -así llaman los indios a sus chalecos sin manga y ruanas a rayas- fueron introducidos en el recinto del senado por Gabriel Muyuy, Jesús Enrique Piñacué o el suplente de Martín Tenganá, Marceliano Jamioy -quien, por su parte, usa también numerosas chakiras, los collares inganos-.

Sucedió también que, por el contrario, algunos de estos elegidos trocaron su ropa de indio por algún traje de blanco. El senador Jesús Enrique Piñacué apareció en la ceremonia de investidura del presidente Andrés Pastrana vestido con conjunto negro y corbata, lo que generó numerosas reacciones. Mientras que en el Cauca muchos deploraron el hecho de que el senador nasa se hubiera vendido tan rápido a las prácticas de los blancos, el periódico El Tiempo, por su parte, elogió su elegancia y buenos usos sociales, no sin cometer un error, irebautizándolo! A este respecto puede señalarse, en efecto, que en un pie de foto que acompañaba una toma de Jesús Enrique Piñacué, el diario anotó: i“El saco para estas ocasiones siempre debe estar abotonado. Las barrigas al aire fueron una constante. Un aplauso para Lorenzo 


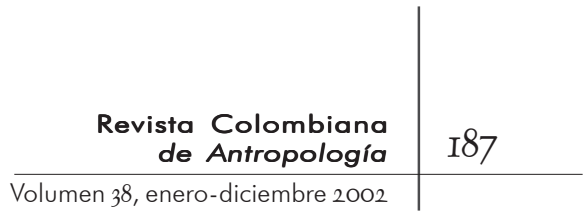

Muelas"! (El Tiempo, 8 de agosto de I998: IOA). Como moraleja de esta historia podría pensarse que si bien es cierto que en política el hábito sí hace el monje, el tigre a pesar de ello no -siempre- es como lo pintan. En este campo, seguramente, más que nunca las apariencias pueden llegar a engañar.

Pertenencias múltiples y variables, impuestas o reivindicadas, a una comunidad, una organización, un partido político, un grupo social, una región o una nación. Y apariencias que las reflejan, también cambiantes, capaces de adaptarse en función de lo que está en juego, los públicos y las circunstancias. Antes descartado de la escena política nacional, a veces manipulado a cambio de su voto, el indio hoy en día está muy presente en ella y, a este respecto, no sólo quiere ser oído sino, también, visto como tal. Objetivos que, sin embargo, sólo tienen sentido bajo la condición de no dirigirse únicamente a poblaciones indígenas $\mathrm{y}$, en consecuencia, de sobrepasar todas fronteras comunitarias para que las pretensiones de pertenencia a una misma nación, hoy concebida como multiétnica y pluricultural -y que entre otros aspectos pasan por vía de la participación en las elecciones- puedan permitir una verdadera renovación de la sociedad colombiana e ir, así, más allá de las apariencias.

\section{Bibliografía}

AbÉLÈs, Marc. 1997. "La mise en représentation du politique”. En Marc Abélès y Jean-Pierre Jeudy. Anthropologie du politique. Armand Colin. París.

Alianza Social Indígena. I994. "Tenemos la memoria, rescatemos la palabra". Mimeo.

— . 1997. "Anatolio Quirá. Cámara de Representantes". Mimeo.

— . I997a. "Todos por Páez”. Mimeo.

_.2000. "Caldono, Camilo Fernández: decisión comunitaria". Mimeo.

. 2000a. "Puracé, Anatolio Quirá: hombre de confianza de todos". Mimeo. 
Bayart, Jean François. I996. L'illusion identitaire. Fayard. París.

Bloque Social Alternativo. 2000. "Todos en minga por el Cauca. Floro Alberto Tunubalá Gobernador”. Mimeo.

Chaumeil, Jean-Pierre. I99o. "Les nouveaux chefs... Pratiques politiques et organisations indigènes en Amazonie péruvienne”. En Problèmes d'Amérique latine. La Documentation française. 96.

Compromiso Colombia. I994. "Por una Colombia al derecho". Mimeo.

Franja Amarilla. 1997. "Jesús Enrique Piñacué. La serenidad que Colombia necesita". Mimeo.

Gruzinski, Serge. I99i. La guerre des Images de Christophe Colomb à 'Blade Runner' (I492-2019). Fayard. París.

JaCANAmijoy, Benjamín. I997. "Preserva tu cultura, revive la tradición". Mimeo.

Laurent, Virginie. I998. "Pueblos indígenas y espacios políticos en Colombia: tendencias nacionales, diferencias regionales". En Modernidad, identidad y desarrollo. Construcción de sociedades y re-creación cultural en contextos de modernización. María Lucía Sotomayor (editora). Ican-Colciencias. Bogotá.

- 200I. "Relato de una campaña electoral 'algo distinta': la experiencia del municipio de Páez (Cauca, Colombia), I997". Contribución presentada en el coloquio internacional Formas de voto, prácticas de las asambleas y toma de decisiones. Un acercamiento comparativo. Colima, México, IO-I2 de octubre de $200 I$.

Movimiento Autoridades Indígenas de Colombia. i997. "En minga por Silvia”. Mimeo.

Movimiento Cívico Indígena Campesino. 1994. "Programa de gobierno periodo I995-I997 alcaldía municipal de Caldono. Ex constituyente Alfonso Peña”. Mimeo.

Movimiento Indígena de Páez. 2000. “En minga por Páez”. Mimeo.

SÁnchez, Nestor Raúl (s. f.). "Demanda”. Consejo de Estado, sección quinta-electoral, sala de lo contencioso administrativo. Bogotá. Mimeo.

SAntana, Roberto. 1992. Les Indiens de L'Equateur: citoyens de l'ethnicité? CNRS. Toulouse. 